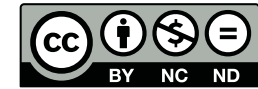

Estudos Teológicos foi licenciado com uma Licença Creative Commons Atribuição - NãoComercial - SemDerivados 3.0 Não Adaptada

http://dx.doi.org/10.22351/et.v58i1.2874

\title{
A EXISTÊnCIA humana COMO RESPOSTA: \\ A ANTROPOLOGIA CRISTÃ À LUZ DA COMPREENSÃo BÍBLICA \\ DO SER HUMANO ${ }^{1}$
}

Human existence as a response:

Christian anthropology in light of the biblical understanding of the human being

\section{Leomar Antônio Brustolin² Leandro Luis Bedin Fontana ${ }^{3}$}

Resumo: O presente artigo indaga pelo sentido antropológico do ser humano no contexto bíblico da criação e da existência humana. A hipótese é que a recuperação de algumas afirmações-chave acerca do ser humano presentes na Sagrada Escritura poderia lançar luz sobre algumas ambiguidades e dualismos existentes em muitas abordagens antropológicas contemporâneas. Uma análise detalhada do conceito hebraico de nefeš revisará a noção ocidental de alma bem como sua sobrevalorização em detrimento da corporeidade. De outro lado, a descoberta da vocação fundamental e pessoal do ser humano à vida e de sua relação estrutural com Deus e seus semelhantes põe em xeque uma atitude imanentista reducionista, que nada vê além dos limites da subjetividade moderna. $\mathrm{O}$ estudo demonstra que a diferença radical do pensamento bíblico-semita em relação ao nosso tempo possui, de fato, um potencial crítico benéfico a qualquer antropologia cristã e mesmo secular.

Palavras-chave: Antropologia. Teologia bíblica. Vocação. Integralidade do ser humano.

Abstract: The present article enquires about the anthropological meaning of the human being in the biblical context of Creation and human existence. The hypothesis is that the recovery of a few key statements about the human being made in the Holy Scripture could shed new light on some ambiguities and dualisms existing in many contemporary anthropological approaches. A detailed analysis of the Hebrew concept of nefeš shall revisit the Western notion of soul, allied with its overemphasis to the

1 O artigo foi recebido em 05 de maio de 2017 e aprovado em 13 de junho de 2017 com base nas avaliações dos pareceristas ad hoc.

2 Doutor em Teologia pela Pontificia Università San Tommaso, em Roma, Itália (2000). Professor e coordenador do Programa de Pós-Graduação em Teologia da PUCRS, em Porto Alegre/RS, Brasil. Contato: leomar.brustolin@pucrs.br

3 Doutor em Teologia pela Philosophisch-Theologische Hochschule Sankt Georgen, em Frankfurt, Alemanha (2016). Bolsista PNPD/CAPES vinculado ao Programa de Pós-Graduação em Teologia da PUCRS, Porto Alegre/RS, Brasil. Contato: leandro.fontana@pucrs.br 
detriment of corporality. On the other hand, the discovery of human being's personal and fundamental vocation to life as well as of his structural relation with God and his/her fellow humans challenges immanentist, reductionist attitudes, which can see nothing beyond the limits of a modern subjectivity. The study shows that the radical difference of the Semitic-biblical framework in relation to today's has indeed a critical power, which is beneficial to any Christian and even secular anthropology.

Keywords: Anthropology. Biblical theology. Vocation. Wholeness of human being.

\section{Introdução}

A época em que vivemos é marcada por mudanças profundas, sobretudo culturais. Dissolve-se a concepção integral do ser humano, sua relação com o mundo e com Deus. Essa cosmovisão altera, indubitavelmente, o modo de pensar e o estilo de vida das pessoas. Frente aos desafios impostos pelos processos de secularização das sociedades ocidentais, pela ditadura da razão instrumental, pela desmitificação da vida humana operada pela ciência e pelos crescentes fundamentalismos religiosos, o ser humano contemporâneo sente-se ameaçado em seu núcleo mais íntimo e a crise de sentido parece assaltá-lo de todos os lados.

Quem sou eu realmente? De onde venho? O que dá sustentação à minha existência? O que fazer com minha vida? Para onde ir? Por certo, essas perguntas clássicas da filosofia e da antropologia não se deixam responder, exclusivamente, com conteúdos de matriz religiosa. Isso não implica, no entanto, abandonar o manancial de significado da tradição judaico-cristã de cujas águas, em todos os tempos da história, em meio à sina humana, buscou-se beber. Aliás, a hipótese que permeia e motiva este artigo é a conjectura de que a recuperação da antropologia cristã bíblica integral e solidária poderia lançar luz sobre as ambiguidades do contexto atual bem como superar os grandes impasses na vivência da fé cristã, ancorados numa visão parcial e redutora tanto do ser humano como de suas relações com o mundo e com Deus. Afinal, não é possível omitir-se diante dos riscos que esse novo cenário representa para a ética, para a formação da pessoa e mesmo para a vivência religiosa.

Em vista disso, o presente artigo propõe-se a resgatar alguns elementos da antropologia bíblica ${ }^{4}$ que permitem superar opções existenciais provisórias, decisões frágeis e espiritualidades superficiais. Às perguntas fundamentais da existência humana postas acima a Sagrada Escritura, respeitadas as diferenças dos escritos que a compõem, responde com uma alusão à vocação fundamental do ser humano: ser criatura e manter viva a relação criatural amorosa com o Criador. O que se sugere neste artigo é,

\footnotetext{
4 Não obstante a consciência dos riscos do constructo "antropologia bíblica", como se essa fosse linear, uniforme e unívoca através dos livros sagrados, o artigo é motivado por um interesse sistemático que, longe de ignorar as diferenciações e profusas discussões exegéticas em torno dos temas abordados, as considera de forma sistemática, o que parece soar como uma contradição. No entanto, os riscos de uma teologia sistemática que prescinda do diálogo com a exegese bíblica e as ciências históricas parecem ser ainda mais perniciosos à teologia e à mensagem cristã do que teologias ou exegeses extremamente diferenciadas, porém inflexíveis e fragmentadas.
} 
pois, que o ser humano bíblico, face à pergunta sobre si mesmo, longe de limitar-se a uma reflexão de cunho estritamente filosófico ou metafísico, descobre sua identidade mais profunda no diálogo com seu Criador, compreende seu agir no mundo à medida que descobre a tarefa ou missão particular que o Criador lhe confia e vislumbra seu futuro à luz de uma promessa que lhe é feita nessa relação.

Com isso, introduz-se, também, o método dessa investigação. Tal como o fora para os escritores bíblicos, os critérios de validação para as respostas às questões centrais da existência humana serão buscados em diálogos bíblicos com o Criador ${ }^{5}$, sejam eles diretos, indiretos, ou em forma de prece, uma vez que esses revelam como uma estrutura antropológica fundamental pode iluminar a reflexão. Deste modo, a resposta ao chamado divino permite ao ser humano autocompreender-se: quando sai de si mesmo para responder à sua vocação pessoal, o ser humano encontra o sentido de sua existência. O conhecimento do humano passa pela antropologia, que lhe dá suporte, uma vez que essa é sempre uma autocompreensão do sujeito. Ela não é um saber sobre o sujeito, mas um saber do sujeito. A experiência de tornar-se sujeito é, por sua vez, sempre situada, interpenetrada de presenças: do eu, do outro e do mundo. Daí a necessidade de uma antropologia que dê conta da complexidade dessas relações e que parece estar implícita nos textos sagrados.

\section{Antropologia bíblica: unidade e integralidade}

\section{Aproximação aos textos bíblicos}

Qualquer abordagem antropológica hermenêutica inspirada nos textos bíblicos esbarra com dois enormes obstáculos: a linguagem e a cultura. Com razão, pois, o exegeta alemão Hans Walter Wolff inicia o seu estudo sobre a antropologia veterotestamentária chamando a atenção para o emprego de uma das palavras hebraicas mais mal compreendidas e, ao mesmo tempo, mais significativas para a compreensão do ser humano bíblico: o substantivo nefeš (נְֶֶֶ). Das 755 ocorrências desse termo na Bíblia

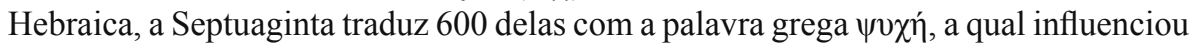
enormemente as traduções latinas cristãs para "anima" e seus derivados alma, âme e correspondentes. Hoje, segundo esse mesmo autor, bem poucas são as passagens nas quais o termo hebraico nefeš de fato equivale ao que definiríamos, na cultura ocidental, como alma, soul ou Seele. ${ }^{6}$ Sua gama semântica varia entre garganta ( $\left.\mathrm{Pv} 25.25\right)$, pescoço (S1 105.18), desejo (Dt 23.25), alma (Jó 19.2), ser animado (Gn 2.19), hálito ou respiração (2Sm 16.14), vida (Lv 24.17-18) e pessoa ( $\operatorname{Sv} 23.30){ }^{7}$

\footnotetext{
Serão destacados, por exemplo, no Antigo Testamento, os relatos da criação, da vocação de Moisés e alguns profetas e determinados salmos. No Novo Testamento, a figura central será a de Jesus Cristo.

6 WOLFF, Hans Walter. Antropologia do Antigo Testamento. São Paulo: Loyola, 1975. p. 21.

7 WOLFF, 1975, cap. 2. Note-se que as citações bíblicas sugeridas acima são apresentadas apenas a título de exemplo, sendo necessário, para maiores esclarecimentos e diferenciações, uma consulta à obra de Wolff no capítulo indicado.
} 
Isso demonstra, para o teólogo Bernd Janowski, o quanto é preciso aguçar a consciência para a necessidade urgente de eliminar os últimos resquícios de uma antropologia essencialista que se arroga o direito de definir o ser humano de todos os tempos e culturas de forma uniforme e invariável. ${ }^{8}$ Para a necessidade de nos livrarmos de uma antropologia que nos mantém cativos em nossas categorias e nos impede de perceber a originalidade e a diferença radical da antropologia do Antigo Testamento em relação às nossas e a outras antropologias.

\section{O que é o ser humano no Antigo Testamento?}

A primeira afirmação bíblica significativa ${ }^{9}$ a respeito do ser humano encontra-se ao fim do segundo relato da criação, em Gn 2.7. Conta-se, ali, como o homem [sic] foi criado, enfatizando-se dois atos do "Senhor Deus": modelou o homem ('adam) com a argila do solo ('adamah) e insuflou em suas narinas um hálito de vida. São precisamente esses dois atos divinos que fazem do ser humano ('adam) um ser animado vivente (nefeš ḩayyah). Note-se que a diferença fundamental, nesse texto, não é entre corpo e alma, mas entre "corpo real e vida" ${ }^{10}$. De acordo com essa compreensão, só podem existir seres animados, vivos, nessa combinação. De fato, segundo Wolff, muito ao contrário da concepção grega de alma, nefeš jamais assume “[...] a significação de um núcleo da existência indestrutível, em oposição à vida corporal, podendo existir

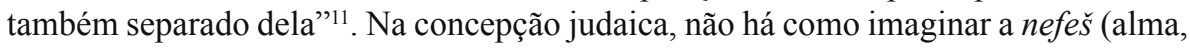
vida, respiração) dissociada do corpo.

Ademais, nefě̌, que, em algumas circunstâncias, também pode ser traduzida por garganta, goela (Is 5.14; S1 107.9; Pv 10.3), está intimamente ligada ao órgão da respiração, isto é, a um elemento essencial à vida (cf. Gn 35.18; 1Rs 17.21-22). Trata-se do hálito vital que é sopro de vida, o respirar. O corpo respira. Enquanto baśar (carne, corpo), o corpo é sistema, vida imanente. No entanto, fechado em si mesmo, nada o poderia distinguir de um cadáver. Tal como o seu sistema imanente necessita do ar externo que entra nos pulmões, assim também o corpo, enquanto unidade sistêmica, necessita de um sopro vital, nefeš, que procede de fora de si mesmo, sendo-lhe transcendente, para lhe dotar de vida. Segundo a compreensão judaica, o ser humano não pode existir sem esse hálito vital. Por isso, nefeš é vida e designa, igualmente, o

8 JANOWSKI, Bernd. Der ganze Mensch: Zu den Koordinaten der alttestamentlichen Anthropologie. Zeitschrift für Theologie und Kirche, v. 113, n. 1, p. 1-28, 2016. p. 4; para uma visão mais ampla de seus estudos, cf. JANOWSKI, Bernd; LIESS, Kathrin (Orgs.). Der Mensch im alten Israel: Neue Forschungen zur alttestamentlichen Anthropologie. Freiburg im Breisgau; Basel; Wien: Herder, 2009.

9 Significativo, pois, além de ser substancialmente mais antigo do que o da tradição sacerdotal de Gn 1 , esse relato pressupõe uma antropologia e uma cosmologia muito distintas daquele. Importa não tanto seu "lugar" no universo, mas sua constituição primária essencial e seu universo de relações. Cf. SOGGIN, Alberto. Alcuni testi-chiave per l'antropologia dell'antico testamento. In: DE GENNARO, Giuseppe (Org.). L'Antropologia biblica. Napoli: Edizioni Dehoniane, 1981. p. 53; RAD, Gerhard von. Das erste Buch Mose: Genesis. 12. ed. Göttingen: Vandenhoeck \& Ruprecht, 1987. p. 52-53.

${ }^{10}$ RAD, 1987, p. 53.

11 WOLFF, 1975, p. 34. 
ser humano inteiro. Significa a vida de uma pessoa concreta que está viva (Gn 9.4; Lv 24.17-18; Pv 8.35). Aliás, nefeš é um conceito aplicado não apenas ao ser humano, mas a todo ser vivente (cf. Gn 2.19). ${ }^{12}$

Um último exemplo que poderia ser mencionado para ilustrar a riqueza semântica da palavra nefeš, que, em hipótese alguma, pode ser reduzida à ideia de alma, é o conhecido Salmo 42. Ali, o salmista, provavelmente no exílio, expressa, em sua amarga oração de lamento, através da metáfora da sede, um desejo profundo de (re)encontro com o Deus vivo. Algo que fora, outrora, uma experiência profunda de sua presença parece-lhe, agora, tão distante. ${ }^{13}$ Nesse caso, nefeš representa a totalidade da pessoa e remete a esse relacionamento vivificante com o Deus vivo (êl hay). "A minha nefeš tem sede de Deus, do Deus vivo" (Sl 42.2). ${ }^{14}$ Indica, assim, que o ser humano inteiro, exterior e interior, é anseio pelo Deus vivo e verdadeiro, pois lhe deve esse sopro vital e vive dessa relação fundamental.

O contraponto de nefeš, na tradição judaica, é baśar (רฺฺָָָָ), traduzido por carne, corpo, parentesco, fragilidade. Indica a condição fundamental do ser humano, enquanto ser criado, dividida com os animais, a qual é marcada pela "fragilidade e precariedade (cf. S1 78.39: Is 40.6-7)"'15. Não por acaso, 104 das 273 ocorrências do termo baśar referem-se a animais. ${ }^{16}$ Longe de representar a corruptibilidade e falência do ser humano, como no helenismo, baśar pretende expressar a condição de criaturalidade e fraqueza dos seres criados, os quais, sem o sopro divino (rûah / רֵּר ), nada mais seriam que pó (cf. Jó 34.14-15; Gn 6.3). Assim sendo, baśar indica que a condição humana é frágil e vulnerável. ${ }^{17}$ Implica não apenas uma disposição para a desintegração física, isto é, para adoecer, envelhecer e morrer, mas também moral, ou seja, para a incapacidade de permanecer fiel à aliança com Deus e obediente à sua vontade. ${ }^{18}$

Comum a esses dois termos (baśar e nefeš) é a convicção de que a vida humana é, acima de tudo, dom do Criador. Deve a sua existência à brisa, ao vento, ao "Espírito de Deus" (rûaḥ-'êl). Enquanto baśar e nefeš apontam para o ser humano limitado, fixado no imanente, rûah remete ao dom divino, à relação dialógica entre o ser humano e Deus, revelando, assim, antropologicamente, a sua dependência absoluta e a abertura fundamental do ser humano ao transcendente.

Ora, ainda que se pense a pessoa humana com categorias de pensamento ocidentais tradicionais de corpo, alma e espírito, o paradigma semita sugere que deva haver uma integração fundamental entre elas. O ser humano, portanto, não tem corpo,

12 WOLFF, 1975 , p. 37.

13 JANOWSKI, 2016, p. 13.

14 Embora a grande maioria das Bíblias traduza, neste caso, nefeš por alma, não há como compreender o drama existencial do autor do salmo, na opinião de Janowski, se nefě̌ for simplesmente reproduzida com a palavra alma, segundo suas acepções ocidentais, e se o seu horizonte semântico mais amplo for ignorado. Ele próprio traduz nefeš, nesse salmo, por vida (JANOWSKI, 2016, p. 13).

15 SCALABRINI, Patrizio Rota. Uomo. In: PENNA, Romano; PEREGO, Giacomo; RAVASI, Gianfranco (Orgs.). Temi teologici della Bibbia. Cinisello Balsamo: San Paolo, 2010. p. 1.473.

16 WOLFF, 1975, p. 43.

17 RAVASI, Gianfranco. L'uomo della Bibbia. Bologna: Dehoniane, 2014. p. 12.

18 WOLFF, 1975 , p. 50. 
ele é corpo; não possui espírito, ele é espírito; não tem alma, ele é alma. Essa convicção é tão radical que a própria aparência física de Saul parece confirmar que ele deva tornar-se rei (cf. 1Sm 10.23; Sl 45.3) ou que fluidos corporais involuntários possam tornar uma pessoa impura (cf. Lv 15.1-33), sem que, com isso, se caia num externalismo vazio. ${ }^{19}$ Essa concepção unitária e semita do ser humano reflete, grosso modo, o pensamento antropológico do Antigo Testamento. A questão é, no entanto, como o ser humano pode perceber ou tornar-se consciente dessa unidade indissolúvel que ele é.

Aqui é preciso remeter a um último elemento da tradição veterotestamentária que é de suma importância para os estudos de antropologia: o termo leb (לב (לב)) e seu equivalente lebab (לבָב), traduzidos como coração. Por somarem 858 ocorrências ao longo do Antigo Testamento, esses dois termos adquirem uma relevância antropológica toda particular. Há, porém, que prestar atenção ao seu universo semântico, dada a sua diferença em relação a acepções modernas do termo. De modo geral, expressa a interioridade do ser humano, seus sentimentos, sua intimidade. Para os ocidentais, o coração traduz sobretudo a vida afetiva. Na concepção semita, porém, a abrangência é mais ampla, pois envolve o afeto, o intelecto, a emoção, a decisão, a vontade e todas as atividades do espírito. ${ }^{20}$ Por isso, na Bíblia, a palavra "coração" distancia-se de um mero sentimentalismo. O coração, no contexto veterotestamentário, "[...] é a sede da vontade, das decisões e da ética"21.

É no coração, portanto, que a pessoa "planeja seus caminhos (Pv 16.9)", decide o seu rumo, discerne entre o bem e o mal. É o "lugar" onde a Lei do Senhor (a Torá) é meditada, seus estatutos são estudados com rigor intelectual e sua vontade é discernida. O coração, em outras palavras, é o grande lugar de integração da experiência humana sob cujo teto corpo e alma, afetividade e razão, vida e espírito encontram, todos, acolhida e habitação. Aliás, é nesse sentido de totalidade e indivisibilidade que se pode compreender, inclusive, o amor total e exclusivo a Deus de Dt 6.5: "Portanto, amarás ao Senhor teu Deus com todo o teu coração (lebab), com toda a tua alma/vida (nefeš) e com toda a tua força (me'od)" ${ }^{\prime 22}$. Também nesse caso nefeš indica toda a interioridade ou tensão interior do ser humano. ${ }^{23}$

Nesse ponto, contudo, é necessário, uma vez mais, cautela, a fim de não confundir a noção semita de coração ou "interioridade" com a compreensão moderna do termo. Para tanto, o biblista e especialista norte-americano em civilizações e línguas do Oriente Médio Antigo, Robert A. di Vito, desenvolveu um estudo muito útil para compreender a radicalidade da diferença entre ambas. Baseado nos sólidos es-

19 DI VITO, Robert A. Old Testament Anthropology and the Construction of Personal Identity. Catholic Biblical Quarterly, v. 61, n. 2, p. 217-238, 1999. p. 233.

20 Para uma visão geral dessas dimensões, cf. WOLFF, 1975, p. 61-85.

21 RAVASI, Gianfranco. Che cos'è l'uomo?: Sentimenti e legami umani nella Bibbia. Cinisello Balsamo: San Paolo, 2012. p. 15 (tradução nossa).

${ }^{22}$ Nos evangelhos sinóticos, Dt 6.5 é sempre apresentado em estreita ligação com Lv 19.18b, formando, assim, o "duplo mandamento do amor" (Mc 12.28-34; Mt 22.34-40; Lc 10.25-28) e dando ainda maior visibilidade à unidade fundamental existente entre vida/experiência humana e vida/experiência espiritual.

${ }^{23}$ BARBAGLIO, Giuseppe. Uomo. In: ROSSANO, Pietro; RAVASI, Gianfranco; GIRLANDA, Antonio (Orgs.). Nuovo dizionario di teologia bíblica. 3. ed. Milano: Paoline, 1989. p. 1.592. 
tudos do exegeta escocês do Antigo Testamento James Barr e do filósofo canadense Charles Taylor, ele compara a noção de interioridade moderna, tal como analisada por Taylor ${ }^{24}$, a saber, como um dos pilares mestres na "construção" de identidades modernas, com as compreensões de identidade semitas antigas, estudadas por Barr. Para ele, ao passo que o indivíduo moderno se autocompreende, em primeira linha, como autossuficiente, autônomo, "desengajado" e "protegido" de seu meio e de suas relações sociais ${ }^{25}$, dependente, primariamente, do universo de sentidos descobertos em suas "profundezas internas" ${ }^{26}$, capazes de revelar-lhe o seu "verdadeiro self", di Vito sustenta que o ser humano bíblico não pode construir sua "verdadeira identidade" senão no conjunto de suas relações e papéis sociais, na dependência e vulnerabilidade em relação ao seu meio, incluindo demônios e maus espíritos, e em uma relação de completa dependência heteronômica obediente em relação a Deus e aos outros. ${ }^{27}$ No Antigo Testamento, portanto, a base para a moralidade não é a liberdade humana, mas a obediência fiel a Jahweh. Não é à toa que profetas como Jeremias e Ezequiel pregam, como solução à situação de pecado do povo, a esperança de uma obediência absoluta à lei de seu Deus, a qual será escrita por ele mesmo em seus corações e isenta de mediações e contaminações humanas. ${ }^{28}$ Não que subjetividade, liberdade e responsabilidade humanas fossem dissolvidas por tal heteronomia. O que ocorria é que o ser humano era muito mais suscetível a outras vozes "externas" que não a sua própria, era muito mais permeável, "poroso" - para seguir empregando a terminologia tayloriana.

\section{A perspectiva do Novo Testamento}

O esforço de formular uma antropologia teológica a partir dos escritos do Novo Testamento apresenta-se como uma tarefa bem mais complicada, dado que o propósito desses livros não era o de fornecer uma resposta nem à pergunta "quem é o homem?" nem à pergunta “quem é o homem Jesus de Nazaré?". Os autores neotestamentários ocupam-se, antes, em contar a história de Deus, o qual - e disso todos dão testemunho - age na e através da pessoa de Jesus. ${ }^{29} \mathrm{~A}$ pergunta correta a ser feita não é, portanto, "o que é o homem?", mas o que esse ato livre de Deus, por meio de sua encarnação na história, tal como ocorreu e foi testemunhado no Novo Testamento, revela sobre o ser humano. Destarte, considerando que a preocupação central do Novo Testamento é teológica, e não antropológica, qualquer antropologia com base nesses

24 TAYLOR, Charles. As fontes do self: a construção da identidade moderna. São Paulo: Loyola, 1997. p. $149-270$.

25 TAYLOR, Charles. Uma era secular. São Leopoldo: Unisinos, 2010. p. 43, 60.

26 TAYLOR, 1997, p. 149.

27 DI VITO, 1999, p. 221. O estudo do autor é inspirado, especialmente, na crítica de Barr a modelos antropológico-teológicos que buscam caracterizar a antropologia bíblica como unitária, sem, no entanto, perceber as radicais diferenças em relação a modelos contemporâneos (cf. BARR, James. The Garden of Eden and the hope of immortality. Minneapolis: Fortress, 1993).

${ }_{28}$ Como exemplos, o autor cita Jr 31.31-34 e Ez 36.25-27 (cf. DI VITO, 1999, p. 236).

29 REINMUTH, Eckart. Anthropologie im Neuen Testament. Tübingen; Basel: Francke, 2006. p. 41. 
escritos não poderá ser outra coisa senão uma antropologia teológica - o que se aplica, aliás, de modo semelhante, ao Antigo Testamento.

Em termos de terminologia, não há grandes distinções a serem feitas, dada a origem judaica de Jesus, além de considerar que a maior parte de seus logia e de suas histórias foi conservada e transmitida em círculos judaicos, mesmo que de língua grega. Em grandes linhas, a unidade psicossomática do ser humano é conservada. Os termos soma/sárx, psyché, pnêuma e kardía traduzem, sem muita diferença de significado, as noções hebraicas de baśar, nefeš, rûah e leb, respectivamente. ${ }^{30}$

Essa visão parece, no entanto, ser posta em questão pela "antropologia paulina”, que insiste constantemente na contraposição sôma-pnêuma, corpo-espírito. Todavia, por contraditório que isso possa parecer, é precisamente nesse antagonismo que percebemos quão fiel Paulo permanece à sua matriz de pensamento judaica. Quando ele afirma, em Rm 8.23, que a nossa salvação consiste na "redenção do corpo", ele não se refere ao corpo enquanto tal, mas à natureza humana terrena. ${ }^{31}$ Pois, considerando o verso 11 do mesmo capítulo, é impossível afirmar que haja ressurreição sem corpo. Mas há, obviamente, uma transformação. O corpo terreno (sôma) precisa ser semeado (morrer e ser enterrado) para que seja ressuscitado à semelhança de Cristo (cf. 1Co 15.42-44). O verso 11, ademais, nos ajuda a compreender que Paulo não distingue entre corpo e alma, mas entre corpo mortal (thnêta sômata), em sua totalidade, e o "Espírito do Ressuscitado" (pnêuma tou egeirantos), que habita o/a crente. A mensagem de Paulo não pode, portanto, ser lida como dualismo antropológico. Ele pretende destacar as tensões entre o ser humano e seus limites, enquanto ser ligado ao mundo, e sua abertura ao transcendente. Por conseguinte, a sarx não é estranha ou externa ao ser humano, mas é identificada com a tendência humana de querer viver fechado ao amor de Deus revelado em Jesus Cristo.

Essa análise sumária de alguns textos-chave do Antigo e do Novo Testamentos demonstrou que, em regra, os conceitos hebraicos e gregos sobre o ser humano, que influenciaram na redação dos textos bíblicos para judeus e cristãos, não carregam uma percepção fragmentada e dualista do ser humano. A pluralidade de termos hebraicos e gregos não descreve dimensões ou partes da realidade humana, mas a totalidade e a unidade do ser humano concreto. Ao buscar-se uma resposta à pergunta acerca do ser humano, pois, tanto o Antigo como o Novo Testamento parecem concordar na afirmação fundamental de que a humanidade é algo tão precioso aos olhos de Deus, a ponto

30 Ao mesmo tempo, é impossível negar que não tenha havido leves mudanças de conotações por conta do ambiente cultural do Novo Testamento. Tal como no Livro da Sabedoria, onde a influência do pensamento helenista dualista é inegável (cf. Sb 8.19-20; 9.15; 3.1-4), há alguns trechos do Novo Testamento que parecem carregar essa ambiguidade (ver, por exemplo, Mt 10.28: "Não temais os que matam o corpo, mas não podem matar a alma"). No entanto, essa espécie de "contaminação” cultural é natural e inevitável, e não prejudica a Boa-Nova de Jesus (cf. BARBAGLIO, 1989, p. 1.592).

31 REINMUTH, 2006, p. 232-233. De acordo com esse autor, Paulo não fala de uma $\dot{\pi} \pi \lambda \hat{\tau} \tau \rho \omega \sigma i \varsigma \dot{\varepsilon} \kappa \tau \sigma \tilde{v}$

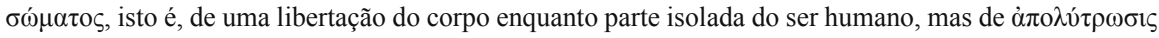

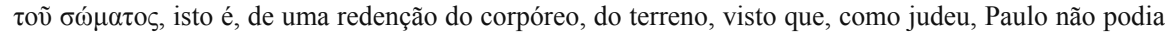
pensar o seu eu separado de seu corpo. Conforme visto acima, o eu judaico não tem um corpo, mas é corpo. 
de o seu amor por ela não conhecer limites. Em uma palavra, se se quer compreender a pergunta “quem é o ser humano?”, numa perspectiva bíblica, e em toda a sua profundidade, essa deve ser primordialmente feita no contexto de total admiração e reverência do salmista: "O que é o homem ('enōš) para dele te lembrares (S1 8.5)?”32.

\section{Cristo: luz para todo ser humano}

Segundo a tradição cristã, a resposta mais clara e definitiva dada por Deus à pergunta feita no Salmo 8, citada acima, é a pessoa de Jesus Cristo. Como bem colocou o teólogo alemão Eberhard Jüngel, para poder-se chegar a qualquer compreensão cristã tanto de Deus como do ser humano, “[...] não se pode nem emitir juízos sobre o ser humano a partir de uma ideia preconcebida de Deus nem juízos sobre Deus [...] a partir de uma ideia preconcebida do ser humano, mas somente à base daquele único evento [...]"33. Não se pode, portanto, dar uma resposta completa e definitiva sobre o mistério do ser humano ignorando a pessoa de Jesus Cristo. Em uma palavra, qualquer antropologia teológica cristã possui uma orientação cristológica. Tudo o que a teologia tem a dizer sobre Deus e sobre o ser humano ela o diz com base na história singular de Jesus Cristo.

A pessoa de Jesus Cristo não é, pois, tão somente um ser humano extraordinário que passou, brevemente, pela história, marcando-a através de palavras inauditas e feitos portentosos. Sua encarnação na história tem um significado universal, uma vez que ele foi "[...] o primeiro de uma humanidade nova a remeter o existir humano ao seu sentido definitivo e a realizar, de forma original, a imagem final do ser humano, tal como Deus a pensou desde sempre" ${ }^{34}$. É exatamente nesse sentido que Paulo o de-

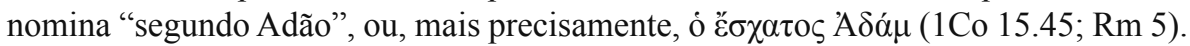
E não apenas isso. Para Paulo, Jesus Cristo é, também, "a imagem do Deus invisível" (Cl 1.15). É na imagem de Jesus Cristo, do novo homem, que conhecemos o rosto de nosso verdadeiro Deus. Assim, a resposta tanto para o mistério humano como para o divino pode ser buscada em sua pessoa.

\section{A integralidade do ser humano}

Algumas pessoas, ainda hoje, separam alma e corpo, fé e vida, igreja e sociedade, Deus e o mundo. A dualidade dessas realidades não pode converter-se em dualismo. Sem sombra de dúvida, essa dicotomia é fundada num equívoco de ordem antropológica, a saber, tanto a visão de que a alma é boa e a carne é má, como a de que não interessa o espírito, mas somente os impulsos da vontade satisfeitos na liberdade absoluta de cada ser. Visando, pois, superar tais compreensões antropológicas limita-

32 PRÖPPER, Thomas. Theologische Anthropologie. Freiburg im Breisgau: Herder, 2011. v. 1, p. 59.

33 JÜNGEL, Eberhard. Der Gott entsprechende Mensch: Bemerkungen zur Gottebenbildlichkeit des Menschen als Grundfigur theologischer Anthropologie. In: JÜNGEL, Eberhard. Entsprechungen: GottWahrheit-Mensch. 3. ed. Tübingen: Mohr Siebeck, 2002. p. 297. (tradução nossa).

34 PRÖPPER, 2011, v. 1, p. 67. (tradução nossa). 
das e reducionistas bem como problematizar a chamada "mística da alma", o teólogo português José Tolentino Mendonça tem insistido, recentemente, numa redescoberta da mística como algo integral e mesmo cotidiano, ou seja, como algo que necessariamente passa pelos sentidos e que revela não apenas a estrutura fundamental do ser humano, mas a "língua materna" e a "gramática" do próprio Deus. ${ }^{35}$

Tais expressões podem chegar a causar sobressalto em razão de suas consequências para o discurso teológico. Contudo, elas nada mais fazem que devolver à corporeidade humana a dignidade que lhe foi subtraída na relação pessoal do ser humano com seu Criador. O próprio Karl Rahner já advertia, em seu tempo, para os malefícios de uma espiritualidade desencarnada. Segundo ele, na tradição cristã, o espírito nunca "pode ser considerado de tal modo que, para ser plenamente perfeito, deva apartar-se da matéria, ou então, de tal modo que seu total aperfeiçoamento deva crescer na proporção do afastamento das coisas materiais" ${ }^{" 36}$.

A corporeidade não pode ser considerada mero apêndice, ou uma realidade periférica da existência humana, a tal ponto de ser flagelada e sacrificada para o bem da vontade e do espírito. Tampouco pode ser o corpo idolatrado e fortalecido pelo narcisismo. No atual contexto cultural, o corpo perdeu muito de sua dimensão espiritual, sendo reduzido ao centro das vaidades e desejos mais variados. Por isso a sociedade da magreza sofre com a anorexia e o crescimento da obesidade leva à morbidez. $\mathrm{O}$ padrão de pessoa realizada, para muitos, é ser jovem, saudável, magro e belo. $\mathrm{O}$ corpo passa a ser idolatrado. Para chegar a esse estereótipo, pode-se sacrificar o corpo para que ele atinja um ideal nem sempre suportável. Para G. Ravasi, tal fragmentação material na concepção do corpo é denunciada enfaticamente pelo ser humano bíblico, encontrando eco nas palavras do salmista que os compara àqueles que, "[...] adorando os ídolos, tornam-se semelhantes a eles no vazio de sua materialidade" ${ }^{\prime 37}$.

\section{Vocação, identidade e missão}

Tendo-se constatado que o ser humano, segundo a perspectiva bíblica, constitui-se e define-se a partir de suas relações com Deus e com os(as) semelhantes, cabe, agora, desdobrar, sistematicamente, como se dá, de fato, esse processo pessoal de autocompreensão e descoberta antropológica à luz da experiência humana.

\section{O chamado de Deus à vida}

De acordo com o primeiro relato da criação (Gn 1.1 - 2.4a), de redação mais recente que o analisado acima, e de tradição sacerdotal, Deus chama todas as coisas à existência, incluindo o homem e a mulher. Vale constatar que Deus não cria ( $b \bar{a} r \bar{a}$ '), simplesmente, todas as coisas, mas diz (wajjōmer 'elōhîm), antes, o que será criado,

\footnotetext{
${ }_{35}$ MENDONÇA, José Tolentino. A mística do instante: o tempo e a promessa. São Paulo: Paulinas, 2016. p. 12.

${ }^{36}$ RAHNER, Karl. Teologia e antropologia, São Paulo: Paulinas, 1969. p. 56.

37 RAVASI, 2014, p. 12. (tradução nossa; cf. S1 115.8; 135.18).
} 
ou seja, Ele anuncia, chama, dá um nome (wajjiqrā', 'elōhîm) àquilo que quer criar. Homem e mulher são, pois, chamados à vida. Não são eles próprios que determinam o instante inicial de sua existência, mas devem o fundamento de seu ser a Outrem. À vista disso, é possível afirmar, com Karl Rahner, que cada ser humano não tem, simplesmente, um chamado, mas é um chamamento de Deus, um chamado "feito carne" no mundo. ${ }^{38}$ Consequentemente, nenhuma pessoa nasce ao acaso. Todo indivíduo foi pensado por Deus e tem um sentido na sua obra de criação (cf. Jr 1.5; Sl 139.15-16). No entanto, isso implica dizer que o ser humano bíblico descobre o sentido de sua existência não apenas curvado sobre si mesmo, em sua interioridade, mas em diálogo com o Criador e com o mundo criado. No testemunho dos textos bíblicos, percebe-se a consciência dessa estrutura relacional essencial.

\section{O ser humano descobre-se e revela-se em sua missão}

Entretanto, os textos bíblicos revelam, ainda, um segundo elemento: ser criado significa, igualmente, ser enviado ${ }^{39}$ Isso nos remete a todo o discurso de vocação e missão contido na Sagrada Escritura, a começar por Abraão (Gn 12.1-4a), passando por líderes como Moisés (Êx 3.1;15), Gideão (Jz 6.11-24) e Samuel (1Sm 3.1-18), continuando com os profetas (Is 6.1-11; Jr 1.4-10; Ez 1.1-3; Am 7.15) e chegando aos discípulos de Jesus, Paulo etc. Vocação significa chamar alguém (pelo nome) e, biblicamente, designa eleição para uma missão ou função determinada. Ao chamado corresponde uma resposta livre e decidida. Somente há resposta quando se escuta o chamado. O ser humano bíblico se descobre na relação com o Deus que chama. O ser humano não se autocompreende apenas porque Deus lhe confere uma vocação, nem se sente orgulhoso e protagonista de uma missão. O que ocorre é que Deus, ao revelar sua missão a Abraão, a Moisés e aos profetas, ajuda-os a descobrir sua identidade mais profunda. À diferença, entretanto, do modelo contemporâneo, predominantemente subjetivista, a resposta à pergunta "quem sou eu?" não é buscada exclusivamente nas profundezas da interioridade individual, mas, particularmente, no diálogo com Deus e com o mundo.

Esse não é, de forma alguma, um processo pacífico e sereno. Ao tentar definir o que significa autoconhecimento em face ao chamado de Deus, o teólogo católico alemão Thomas Pröpper afirma ser o momento em que "[...] à pessoa chamada é dado conhecer quem ela deveria ser, muito embora ela, por si mesma, não o seja, talvez não o possa ser e, muito frequentemente, não o queira ser" ${ }^{40}$. A pessoa reconhece seus limites e impossibilidades, suas resistências e fraquezas. Nos relatos das "vocações" das personagens bíblicas, há uma série de desculpas para justificar a própria limitação diante do chamado de Deus (cf. Gn 4.9; Êx 3.11; Is 6.5; Jr 1.6; Lc 5.8). Pröpper, no

\footnotetext{
${ }^{38}$ RAHNER, Karl. Sendung und Gnade: Beiträge zur Pastoraltheologie. 5. ed. Innsbruck; Wien: Tyrolia, 1988. p. $97,100$.

${ }^{39}$ GRESHAKE, Gisbert. Wie ist Gottes Ruf erkennbar? In: GRESHAKE, G. (Org.). Ruf Gottes - Antwort des Menschen: zur Berufung des Christen in Kirche und Welt. Würzburg: Echter, 1991. p. 99.

40 PRÖPPER, 2011, v. 1, p. 60. (tradução nossa).
} 
entanto, chama atenção para a resposta de Jahweh: "Eu estarei contigo (Êx 3.12; Jr 1.8)". Em termos antropológicos, a resposta de Deus à pergunta do ser humano sobre si mesmo, ou seja, à pergunta “quem sou eu...?”, é a promessa de sua presença e proximidade. $\mathrm{O}$ que acontece nesse encontro com Deus, segundo Pröpper, não é o desvendamento do mistério humano no sentido científico ou mesmo filosófico. $\mathrm{O}$ que ocorre é que essa pergunta alcança um nível ainda mais profundo pelo fato de que a pergunta pelo mistério do ser humano é colocada em contraste com a pergunta por um mistério ainda maior, que é Deus, o qual, “[...] ao acolher o ser humano, revela-se a ele" "E1. É, portanto, nesse diálogo, nessa "negociação" com Deus que o ser humano bíblico descobre a resposta tanto para a pergunta "quem sou eu” como para a pergunta "quem é Deus". O fato de que a iniciativa, o primeiro passo em direção ao ser humano, proceda de Deus qualifica e determina cada pessoa humana como um "ser respondente". Segundo o autor, esta seria a matriz fundamental da antropologia bíblica: "O ser humano existe diante de Deus (coram Deo) e como resposta à Palavra interpeladora de Deus" ${ }^{42}$.

\section{A resposta única de cada um}

Há que se dizer, contudo, que descobrir o chamado particular feito a cada um, isto é, sua própria ipseidade, é um grande dom. Nem todos(as) têm essa oportunidade. Devido a circunstâncias familiares, oportunidades de trabalho, situações pessoais, muitas pessoas jamais chegam a confrontar-se com questões dessa natureza ou são impedidas de levá-las a cabo. Por outro lado, descobrir o próprio chamado é como descobrir "um tesouro escondido no campo" (Mt 13.44), não obstante as dificuldades que ele implica. Isso exige que a pessoa chamada, consciente de seus limites, torne-se um novo homem, uma nova mulher. Isso, por sua vez, toca a pessoa de forma tão profunda que exige a revisão de toda a sua existência. Essa vocação é tão alta que alguns chegam a mudar seu próprio nome para que a conversão seja ainda mais radical. Abrão se torna Abraão; Jacó vem a ser Israel; Simão, filho de Jonas, se torna Pedro; Saulo passa a ser conhecido como Paulo.

Tal ruptura não significa negar o humano e "subjetivo" para acolher tão somente o sobrenatural. Tampouco implica viver em uma espécie de esquizofrenia onde o ser humano descobre como que dois eus interiores, um humano e outro espiritual, o que poria em xeque a concepção bíblica analisada acima. Ouvir o próprio chamado ou descobrir a própria vocação significa, ao contrário, transpassar a camada superficial das convenções sociais, das dinâmicas pessoais e familiares, dos modelos vigentes de sucesso e atingir um nível mais profundo de consciência e percepção de si mesmo e da realidade. Descobrir o que cada ser humano tem de mais particular e intransferível face à realidade e os desafios que o cerca e interpela. ${ }^{43}$

\footnotetext{
${ }^{41}$ PRÖPPER, 2011, v. 1, p. 61. (tradução nossa).

42 PRÖPPER, 2011, v. 1, p. 61. (grifo do autor; tradução nossa).

43 GRESHAKE, 1991, p. 107.
} 


\section{A liberdade de não responder}

Vocacionado à comunhão com o Criador, o ser humano é livre para responder ou não a esse chamado de amor gratuito. Todavia, quando essa relação é rejeitada, a pessoa como que negligencia uma dimensão essencial de seu ser. Ora, essa possibilidade existiu, já, desde sempre. Segundo o relato genesíaco, Adão e Eva, seduzidos pela serpente, distorcem sua relação com Deus, com as pessoas e com as coisas. Tornam-se prisioneiros do labirinto de sua cisão com o Criador. Como consequência dessa ruptura, a percepção da realidade fica distorcida, já que o ser humano passa a não mais acreditar na Palavra do Criador - "[...] e viu que era muito bom (Gn 1.31)" -, mas acredita ter que interpretar a realidade toda, contando apenas com suas próprias forças e categorias. Adão passa a estranhar sua nudez, a não mais se aceitar tal como fora criado. Esconde-se, desvia o olhar (Gn 3.7). Quando o ser humano rompe sua vocação de resposta ao amor de Deus, acaba por destruir-se a si mesmo. ${ }^{44} \mathrm{O}$ pecado introduz divisões danosas e marcantes na vida do ser humano. As relações são afetadas profundamente. Mas esse é o preço que Deus está disposto a saldar, a fim de salvaguardar a liberdade humana.

\section{Considerações finais}

O presente artigo concentrou seus esforços na formulação de uma antropologia cristã com base nos escritos bíblicos. Apoiada na discussão acerca do conceito hebraico de nefeš (alma, vida respiro etc.), a pesquisa demonstrou haver inconsistências em abordagens antropológicas cristãs contemporâneas nas quais corpo e alma, vida terrena e vida sobrenatural, são apresentadas como elementos antagônicos em conflito, amiúde em detrimento do corpo. Com base nas análises feitas, afirma-se que uma concepção de alma que esteja em oposição à corporeidade e à experiência humana não pode estar alinhada à compreensão bíblica de nefeš, em particular, e do ser humano, em geral. O mundo e a realidade humana não são desprezados ou rejeitados por Deus, mas amados de forma extrema (cf. Jo 3.16). Integrar, pois, de maneira livre e responsável, corporeidade e espiritualidade, antropologia e escatologia, vida ética e mandamentos divinos, eis a tarefa de toda pessoa cristã.

Todavia, assim como há o perigo de negar a realidade humana, a fim de sobrevalorizar a divina, há, também, o risco de o ser humano despencar nas "profundezas internas" de sua interioridade, ficar confinado nos limites do assim chamado "quadro imanente" (Ch. Taylor) e perder de vista o horizonte de sua transcendência. Prescindindo de sua relação com o Criador e com os seus semelhantes, o ser humano perde o contato com a totalidade da existência humana. Ora, essa perda não ocorre sem prejuízos ao ser humano, uma vez que esse, segundo a visão bíblica, encontra sua vocação (ser) e sua missão (agir) particulares no mundo precisamente no diálogo com Deus e com outros seres humanos. Não é negando nem a humanidade nem a divinda-

44 SANNA, Ignazio. Chiamati per nome: antropologia teológica. Cinisello Balsamo: San Paolo, 1994. p. 119. 
de que se pode afirmar o oposto ao que se quer negar, uma vez que aquele só pode ser compreendido e afirmado à luz deste, e vice-versa.

\section{Referências}

BARBAGLIO, Giuseppe. Uomo. In: ROSSANO, Pietro; RAVASI, Gianfranco; GIRLANDA, Antonio (Orgs.). Nuovo dizionario di teologia biblica. 3. ed. Milano: Paoline, 1989. p. 1.590-1.609. BARR, James. The Garden of Eden and the hope of immortality. Minneapolis: Fortress, 1993. DI VITO, Robert A. Old Testament Anthropology and the Construction of Personal Identity. Catholic Biblical Quarterly, v. 61, n. 2, p. 217-238, 1999.

GRESHAKE, Gisbert. Wie ist Gottes Ruf erkennbar? In: GRESHAKE, G. (Org.). Ruf Gottes - Antwort des Menschen: zur Berufung des Christen in Kirche und Welt. Würzburg: Echter, 1991. p. 97-125.

JANOWSKI, Bernd. Der ganze Mensch: Zu den Koordinaten der alttestamentlichen Anthropologie. Zeitschrift für Theologie und Kirche, v. 113, n. 1, p. 1-28, 2016.

JANOWSKI, Bernd; LIESS, Kathrin (Orgs.). Der Mensch im alten Israel: Neue Forschungen zur alttestamentlichen Anthropologie. Freiburg im Breisgau; Basel; Wien: Herder, 2009.

JÜNGEL, Eberhard. Der Gott entsprechende Mensch: Bemerkungen zur Gottebenbildlichkeit des Menschen als Grundfigur theologischer Anthropologie. In: Entsprechungen: Gott - Wahrheit - Mensch. 3. ed. Tübingen: Mohr Siebeck, 2002. 5 v. (Theologische Erörterungen, 2).

MENDONÇA, José Tolentino. A mistica do instante: o tempo e a promessa. São Paulo: Paulinas, 2016.

PRÖPPER, Thomas. Theologische Anthropologie. Freiburg im Breisgau: Herder, 2011. 2 v.

RAD, Gerhard von. Das erste Buch Mose: Genesis. 12. ed. Göttingen: Vandenhoeck \& Ruprecht, 1987. (Alte Testament deutsch, 2-4).

RAHNER, Karl. Sendung und Gnade: Beiträge zur Pastoraltheologie. 5. ed. Innsbruck; Wien: Tyrolia, 1988. Teologia e antropologia. São Paulo: Paulinas, 1969.

RAVASI, Gianfranco. Che cos'è l'uomo?: Sentimenti e legami umani nella Bibbia. Cinisello Balsamo: San Paolo, 2012. L'uomo della Bibbia. Bologna: Dehoniane, 2014.

REINMUTH, Eckart. Anthropologie im Neuen Testament. Tübingen; Basel: Francke, 2006.

SANNA, Ignazio. Chiamati per nome: antropologia teologica. Cinisello Balsamo, Milano: San Paolo, 1994.

SCALABRINI, Patrizio Rota. Uomo. In: PENNA, Romano; PEREGO, Giacomo; RAVASI, Gianfranco (Orgs.). Temi teologici della Bibbia. Cinisello Balsamo: San Paolo, 2010. p. 1.472-1.478. SOGGIN, Alberto. Alcuni testi-chiave per l'antropologia dell'antico testamento. In: DE GENNARO, Giuseppe (Org.). L'Antropologia biblica. Napoli: Dehoniane, 1981. p. 45-62.

TAYLOR, Charles. As fontes do self: a construção da identidade moderna. Tradução Adail Ubirajara Sobral; Dinah de Abreu Azevedo. São Paulo: Loyola, 1997.

2010 . . Uma era secular. Tradução Nélio Schneider; Luzia Araújo. São Leopoldo: Unisinos,

WOLFF, Hans Walter. Antropologia do Antigo Testamento. São Paulo: Loyola, 1975. 